\title{
DO BOUDOIR AO MOTEL: CULTURA VISUAL, IMAGENS DECO- RATIVAS E LUGARES ÍNTIMOS PARA O SEXO
}

\author{
Marize Malta \\ Profa. EBA-UFRJ \\ Doutoranda em História - UFF
}

\section{Resumo}

O texto discute relações intertextuais entre comportamento, imagens, ambientações e imaginações, tomando como referência o sexo e os lugares considerados ideais para sua prática. Espaços íntimos, em casa ou fora dela, com camas e linguagens visuais específicas, são analisados por meio do que sugerem suas decorações e representações, do século XVIII aos dias de hoje.

Palavras-chave: cultura visual, atividade sexual, ambientação.

Of boudoir to the motel: visual culture, decorative images and close places for the $\operatorname{sex}$

\begin{abstract}
From the perspective of intertextuality, this text discusses the relationships between behavior, images, context and imagination, by focusing on sex and the places that are considered ideal for sexual practices. Spaces of intimacy, both inside and outside of the home, which are equipped with specific physical and visual props, are analysed by means of their decorations and representations, from the 18thcentury to the present day.
\end{abstract}

Keywords: visual culture, sexual activity, ambiance. 
Qualquer indivíduo pode ser sensato, desde que não tenha imaginação.

Oscar Wilde

Até o século XVIII, a sociedade européia não considerava imprescindível retirar-se para um local específico a fim de praticar sexo. Nas camas de aparato dos reis ou no monte de feno dos camponeses não era necessária a privacidade de portas vedadas à observação de estranhos nem de decorações de interiores especiais para o ato sexual. Sabe-se, por exemplo, que o rei de França Luís XIV deitava-se com madame de Maintenon, a segunda esposa, enquanto conversava com seu ministro. Contudo, as transformações econômicas, socioculturais e políticas que se operaram nos setecentos ensejaram novos padrões comportamentais em casa ${ }^{1}$ e fora dela ${ }^{2}$, que, pouco a pouco, buscaram na intimidade uma das formas de individualização do homem coletivo. O sujeito queria estar sozinho ou ficar com quem desejasse sem a intromissão de quem não havia sido convidado. Com essa atitude, o sexo se isolava em algum lugar de casa e incrementava-se o processo de criar imagens porta adentro que evocassem o sexo. Entre quatro paredes, a atividade sexual passou a ser traduzida por representações visuais ambientais. Que lugares foram esses? O que incluíam e deixavam de fora para permitir associações com idéias de sexo?

Se camas e quartos de dormir ${ }^{3}$ hoje podem suscitar imagens com sexo, é porque atribuímos a essa combinação - de lugar (o quarto) com objeto (o móvel cama) - a tradução de práticas sociais vigentes, a representação dominante de imagens vivenciadas por uma sociedade que tem preferido fazer sexo com portas fechadas. Mas nem sempre o sexo se faz e se fez associar visualmente em todos os quartos e camas. Como o quarto de dormir abriga outras atividades além do sexo e este não é considerado como algo aceitável de ser mostrado em público, dificilmente a decoração dos quartos inclui apelos visuais que simbolizem as preferências ou práticas sexuais de seu proprietário. Os dormitórios em geral permanecem imaculadamente assentados em representações aceitas pela moral vigente e aparentam, de forma inequívoca, um lugar onde pessoas apenas dormem, descansam, relaxam.

Imaginemos uma moça que convida, por pura vontade, um rapaz para fazer sexo em seu apartamento; o quarto é decorado do seguinte modo: janelas cobertas por pesadas cortinas de veludo solferino; cama redonda fartamente estofada; lençóis de cetim vermelho; amplo espelho no teto; carpete macio grená; paredes revestidas com damasco carmim brocado; luz mortiça. Esses objetos e revestimentos, nessas cores, nessas condições, nesse lugar, nesse tempo, dessa 
pessoa, constroem uma representação que pode ser codificada como 'aqui é lugar onde só se faz sexo', dentre outras coisas. O rapaz, certamente, não vai associar a dona daquele quarto à bela adormecida, muito menos a uma figura maternal. Podemos imaginar o ele vai pensar da moça.

Os espaços interiores, como outros tipos de imagens, têm seus códigos visuais particulares e devem ser igualmente considerados em estudos afiliados à cultura visual ${ }^{4}$. São imagens peculiares, de certo, porque formadas por objetos concretos inseridos em espaços construídos, mas nem por isso menos instigante e menos importante. Nos ambientes interiores, revestimentos e móveis, enfeites e outros objetos se interconectam e formam um conjunto visual, onde composições de vazios e cheios procuram representar modos de ver o mundo e expressar as personalidades de quem neles convive. Permanecemos muito mais tempo em lugares fechados do que na exterioridade, passamos a maior parte de nossas vidas envoltos em objetos, móveis e revestimentos. Entretanto, pouco refletimos sobre a experiência visual cotidiana que esses espaços nos proporcionam e raramente pensamos em sua participação na construção de nossa cultura visual.

A noção de cultura visual engloba objetos tratados nas histórias da arte e do design e inclui outros, freqüentemente superolhados ou ignorados por elas ${ }^{5}$. É importante lembrar que “(...) enquanto a história da arte se guia por objetos individuais, os estudos visuais procuram expandir questões sobre o estatuto do objeto artístico para o universo mais geral das imagens e das representações visuais". ${ }^{6} \mathrm{~A}$ decoração dos ambientes interiores não abrange objetos exclusivamente artísticos nem frutos do design. Sua complexidade não é devidamente contemplada por meio de estudos que tomam isoladamente as disciplinas da história do design e da história da arte, que tratam o objeto 'decoração' com reservas e, por vezes, indiferença.

Diferente da planaridade de imagens em telas, fotografias, estampas e propagandas, os ambientes interiores tratam de um espaço tridimensional, mutante, composto por uma junção de vários pontos de vistas, tomados por diversas distâncias focais ${ }^{7}$. Ora se vê todo o ambiente, ora se percebe detalhes. Quando se está sentado, pode se observar um objeto no seu melhor ângulo; quando em pé, é possível olhar detalhes da estampa da cortina, por exemplo. Ao se deitar, um novo ângulo mostra o lustre que pende do teto e no momento em que se passeia pelo ambiente, várias tomadas ${ }^{8}$ são visualizadas. E assim por diante. A experiência visual porta adentro ${ }^{9}$ trata de imagens no espaço e no tempo que não conseguem ser apreendidas por esquemas unilaterais. Cada tipo de ambiente em relação à sua configuração decorativa requer variadas tomadas para melhor ser entendido. Abordá-lo por diversos ângulos é considerar a variedade de conceitos que estão em jogo, estreitamente vinculado à experiência visual porta adentro cada um com sua versão. Pensar em lugares decorados exclusivamente para a 
privacidade sexual, para retomar o assunto do artigo, é lidar com variadas imagens e associações que lidam com conceitos sobre sexo, erotismo, intimidade, privacidade e também participam da construção de seus sentidos. Sexo, intimidade, quarto e cama nem sempre estiveram associados.

Desde os tempos medievais o lugar onde se dormia não era isolado do resto da casa, mas se localizava no grande salão, junto com outras atividades. Não havia noção de vida interior nem de autoconsciência ${ }^{10}$. Não existia privacidade e idéia de interior, conceitos construídos mais tarde ${ }^{11}$. As camas eram enormes, verdadeiros locais coletivos. Por esse viés, o sexo não encontrava um abrigo próprio e, em geral, sua prática acabou relacionada, pelo menos nos contos eróticos, aos lugares mais reclusos desses tempos: os conventos e mosteiros. Do século XV ao século XVII, mesmo com subdivisão mais detalhada de cômodos, operada de forma gradual, a questão da privacidade pouco avançou. Tradicionalmente os quartos dos soberanos, inseridos em Maisons Royales $^{12}$, deveriam aparentar poder, grandeza e riqueza. Eram símbolos dos atributos do monarca e de seu país, sendo locais públicos. As camas - chamadas de lit de parade ${ }^{13}$ - eram revestidas de materiais raros e caros, enfeitadas com bordados e acessórios colocados para impressionar o visitante. Para conversas mais amiúde, atividades de escrita com maior concentração, encontros reservados, os homens da Coroa podiam contar com cômodos menores, contíguos aos seus quartos, os cabinets. Eles abrigavam variadas atuações e, dependendo das preferências do seu proprietário, guardavam também suas coleções (particulares), em que poucos punham os olhos. Até onde se sabe, havia na Paris do século XVII, no palacete de JeanBaptiste Lambert de Thorigny - o Hôtel Lambert -, um gabinete decorado com o tema do amor, o que leva a crer que seria um quarto decorado para encontros amorosos. Porém, não se tratava necessariamente de lugar de total privacidade.

Somente a partir do século XVIII, nos círculos aristocráticos e burgueses europeus, as noções de privacidade e intimidade começaram a ser associadas aos interiores domésticos e aos ambientes porta adentro passaram a ser referências visuais para essas noções. Facilitando satisfazer o desejo por intimidade, as chamadas camas de alcova - lit d'alcove ou lit à la niche - foram introduzidas nos ambientes domésticos, que adotavam subdivisões de cômodos cada vez mais pormenorizadas ${ }^{14}$. Localizada em um nicho da parede e escondida atrás das cortinas, a cama de alcova encontrava um lugar recluso, secreto e dissimulado. Ela lidava com a noção de um interior (o nicho) dentro de um outro interior (o quarto), provocando uma imagem de forte intimidade. Além da cama de alcova, houve um cômodo típico do período que simbolizou também a idéia de refúgio, de querer estar só, de encontrar alguma privacidade. Esse novo cômodo denominava-se boudoir. Poderia ser simplesmente um vestiário, um quarto ou uma sala 
íntima, mas, antes de tudo, era um espaço de privacidade. Não foram, porém, as atividades de troca de roupa, repouso ou socialização seletiva que acabaram por caracterizar esse cômodo exclusivamente feminino. Ele foi identificado como o local privilegiado dos encontros amorosos e que convidava à reflexão sobre o direito da intimidade - meditativa ou sexual. O boudoir parecia configurar uma geografia do prazer íntimo onde a decoração, repleta de espelhos, efeitos ilusionistas e pinturas provocantes, teriam a função de sugerir sua atividade principal o sexo - e estimular os amantes. O sexo encontrava um lugar em casa, uma imagem decorativa, um espaço privilegiado e privado.

O lugar da intimidade, e do sexo, também se associou a uma linguagem decorativa: o rococó, o primeiro estilo desenvolvido exclusivamente para interiores. A decoração refinada, detalhista, contínua e integrada empregou linhas caprichosas, de exotismo oriental e de um naturalismo falacioso. As fantasiosas curvas rocailles, que envolviam o cenário, pareciam artificiosamente pensadas para o amor e prazer. Suas ondulações pareciam não ter fim: cada curvatura emendava-se em outra linha sinuosa que se entrelaçava em outra silhueta flexível e, assim, os contornos das formas pareciam dizer de vontades que queriam se desvencilhar de ordens, simetrias, regras rígidas.

Eros era acolhido como o mito guardião dos boudoirs em meio a curvas encantadoras, contrastes de cores diversas com toques dourados e idéia de unidade compositiva pelo efeito. Diante de variadas gravuras ${ }^{15}$ que ilustraram livros eróticos, tanto do período quanto posteriores, é flagrante o predomínio da linha rococó nas ambientações das cenas retratadas, provocando associações do estilo com um caráter libidinoso. No livro L'académie des dames, de 1787, há uma estampa que sugere uma composição decorativa, com gosto setecentista, com laços de fita e vários membros sexuais masculinos. Com certeza era para decorar um boudoir. O boudoir sendo lugar de volúpia faz parte de uma construção imaginária, como demonstra Michel Delon, no livro L'invention du boudoir ${ }^{16}$, alicerçado principalmente pela abordagem literária. O cômodo foi eleito por diversos romancistas e pelo imaginário coletivo para encenar histórias de sedução, criando uma supra-realidade, repleta de fantasias nunca vividas. Desde sua invenção, decoradores e escritores rivalizavam por fazer do boudoir reduto de seduções e atos sugestivos. O boudoir tornava-se um espaço da imaginação onde não se sabia jamais o que exatamente nele se passava. O sexo, nesse ambiente, estava em segredo. Podia-se fazer sexo às escondidas. Podia-se falar e escrever sobre os segredos de alcova.

O século XVIII é por vezes tomado como o século da volúpia, muito mais pela produção artística - pictórica e literária - do que pelo comportamento libertino da sociedade da época, na realidade bem puritana. A adjetivação, construída 
no imaginário, talvez se explique por ser no século iluminista que surgiu o boudoir; que reinou Luís $\mathrm{XV}$, o rei amante ${ }^{17}$; que se editaram vários romances eróticos e que foram realizadas inúmeras pinturas de apelo sensual e erótico, apesar de tais fatos não gozarem de ineditismo, mas sim de maior repercussão.

Foi grande o número de obras eróticas publicadas no período ${ }^{18}$. Dentre as mais célebres podemos citar: Vénus dans le cloitre (Vênus no claustro) (1719), do abade du Prat; Thérèse philosophe (Teresa filósofa) (1748), do marquês d'Argens; Margot la ravandese (Margot, a tagarela), de Fougaret de Montbron; Erotika Biblioan (Livro erótico) (1783), de Mirabeau. A mais controversa rendeu ao autor, o marquês de Sade, intensa perseguição em vida por ter tido a ousadia de colocar em palavras quase todas as práticas libertinas do ser humano. O livro, La philosophie dans le boudoir (A filosofia no boudoir ou A filosofia na alcova, dependendo da tradução), publicado em 1795, só obteve reconhecimento no século XX com os surrealistas Breton e Apolinnaire ${ }^{19}$, responsáveis por celebraram a liberação do imaginário experimentada por $\mathrm{Sade}^{20}$. Os escritos também influenciaram o aparecimento do adjetivo sadismo (do francês sadisme, criado em 1834), que eternizou, através de um signo, uma das perversões humanas expostas por Donatien Alphonse François de Sade, o famoso marquês.

Ampliando a gama do imaginário erótico do século XVIII, a representação de uma sensualidade, disfarçada ou dissoluta, encontrou eco na obra pictórica de vários artistas franceses, como Fragonard, Greuze, Watteau e Boucher. Criando cenas com personagens mitológicos ou personagens contemporâneos, os artistas encontraram na pincelada rococó a versão perfeita para a sensualidade feminina através de volteios e arrebatadoras curvas, atiçando a imaginação.

Boucher recebeu a alcunha de 'pintor de alcovas', que melhor seria traduzida como 'pintor de boudoirs', tendo em vista que a palavra francesa não encontra tradução satisfatória em nenhuma outra língua. Como pintor do rei Luís XV, por indicação de Madame Pompadour, François Boucher deixou registradas em suas pinceladas imagens que estimulavam a imaginação erótica da corte. Também tinha como tarefa, além de arrebatar a libido alheia, ensinar ao delfim os prazeres do sexo.

Esse hábito de falar, escrever, pintar, esculpir sobre sexo, e até mesmo decorar espaços para esse fim, colocavam o ato, tido como algo natural, consequiência da natureza humana, como um comportamento fora do comum, não banal, especial. O sexo artificializava-se, aproximando-o de uma manifestação da cultura. Desejo, paixão, volúpia transcendiam um ato de instinto animal. O sexo descobria o prazer e os homens se compraziam em escrevê-lo, pintá-lo e fazê-lo intimamente. Somado à conscientização do prazer, a melhoria da higiene permitiu a redução dos índices de mortalidade infantil, fazendo com que os nobres diminu- 
íssem a necessidade de grande número de filhos, favorecendo a disseminação do ato sexual sem finalidades de concepção. O sexo podia ser prazer. Procurava-se um ambiente cuja atmosfera fosse de prazer. Contudo, quando as relações sexuais pareciam ter encontrado um ambiente favorável e certas imagens que propiciassem suas atuações despudoradas dentro das casas, um processo moralizante afastava sua concretização.

Um dos livros mais ilustres a ditar as regras de comportamentos ${ }^{21}$ aceitavelmente cristãos foi escrito por Jean-Baptiste de la Salle, intitulado Les Règles de la bienséance et de la civilité chrétienne (Regras do decoro e da civilidade cristã) editado em 1703 e reeditado por vários anos subseqüentes. A partir da crescente progressão da classe média na escala social, suas regras morais, bem traduzidas por La Sale, foram se tornando paradigmas para toda a sociedade.

Enquanto a realeza e a corte deleitavam-se na luxúria (o povo assim imaginava ${ }^{22}$ ), cada vez mais se enrijeciam as regras de decência. A classe média condenava devaneio, moleza, preguiça e libertinagem vistas como comportamentos próprios da sociedade cortesã, os quais estavam opostamente relacionados aos atributos que idolatravam: trabalho, moralidade, comedimento, decência. Se por um lado, os conceitos de família e lar se fortaleciam, de outro, os quartos conjugais assumiam imagens moralistas, desprovidos de quaisquer símbolos sexuais. Os casais pareciam não praticar sexo naquele ambiente.

O século XIX marcou uma era das mais puritanas da história, sancionado pelo controle estrito das ânsias instintivas. Exacerbava-se a consciência de vergonha ${ }^{23}$ com relação ao próprio corpo e embaraço quando o assunto era sexo. Aliás, não se falava dele em casa nem tampouco se escrevia deliberadamente sobre ele, com o risco de o escritor ser proscrito das prateleiras das bibliotecas públicas e domiciliares ou mesmo preso. Se os manuais de comportamento da Renascença citavam abertamente questões sexuais, mesmo para crianças, os livros do século XIX nem sequer tocavam no assunto. O sexo se tornou sigiloso e clandestino. Onde localizá-lo? Em que ambiente inseri-lo?

O quarto de dormir se transformou em um dos cômodos mais privados e íntimos da casa; uma verdadeira caixa vedada à vista das pessoas e aos instintos carnais - uma fortificação para a castidade. A nudez tornava-se imoral; a visão do próprio corpo nu deveria ser evitada. A cama assumiu uma imagem como se fora feita somente para dormir. Nela não se devia permanecer sem estar entregue ao sono, a não ser em caso de enfermidade. Ao deitar-se, o sinal da cruz auxiliava a espantar os demônios da carne. Brincar na cama, ou mesmo ler, era considerado indecente. Quanto mais fazer sexo!

As regras moralizantes impostas à decoração de interiores dos quartos contrastavam com a idéia de personalização que os mesmos deveriam expressar. 
Buscava-se traduzir individualidades nos espaços interiores, principalmente naqueles lugares mais privados. Era como se nos quartos as pessoas pudessem encontrar seu próprio eu e conseguissem se despir de suas máscaras sociais um ambiente onde o pensamento podia voar alto e os desejos se mostrarem na segurança daquelas quatro paredes íntimas ${ }^{24}$. Mas a liberdade, na intimidade, inexistia. Mesmo sem vigilância expressa de outros, as pessoas sentiam-se observadas, julgadas, muitas vezes por elas próprias ${ }^{25}$.

A moral ganhou um franco aliado no combate a favor da decência: as campanhas sanitaristas, encabeçadas pelos higienistas, dentre os mais importantes, o dr. Michel Lévy que, desde 1844, influenciou uma série de medidas em prol da saúde e moral públicas. Higiene e moral tornaram-se indissociáveis palavras de ordem relacionadas à limpeza. Os recantos obscuros, propiciadores de encontros amorosos, teriam que ser proscritos. Tudo deveria ser desobstruído, ventilado e iluminado. Atenção especial foi dada às camas e em particular à coberta de plumas, que ativava as secreções e favorecia a masturbação, segundo os higienistas. O século XIX marcou o desprestígio da cama como lugar para o prazer. Esse aspecto de esfriamento da libido ganhou representação nas camas em ferro e latão inglesas, tão fortemente aconselhadas e propagandeadas para o 'bem-estar' das famílias.

Decerto que tanto moralismo provocou a corrida masculina aos bordéis, que sempre existiram. Apesar de a palavra bordel só ter surgido em 1609, os locais de prostituição acompanham toda história da humanidade para proporcionar relações sexuais sem a necessidade da conquista. Todavia, não é esse o assunto que nos cabe relatar. $\mathrm{O}$ importante é perceber que a exacerbação do recato e do puritanismo gerou uma sociedade hipócrita, que impetrou principalmente à mulher burguesa, à dona de casa, décadas de repressão sexual, tornando-a praticamente inerte aos apelos da carne ou vítima de histerias ${ }^{26}$, curadas em manicômios. Não era mais admissível que as mulheres possuíssem boudoirs porque deveriam permanecer em locais familiares, onde poderiam ver e ser vistas estar vigilantes e serem vigiadas, alcançando um estado de verdadeiro controle visual e, conseqüentemente, sexual. As mulheres de boa família não encontravam lugar para suas sexualidades. Para os homens, ao contrário, sempre havia uma solução...

Além dos bordéis, chamados no século XIX também de casas de rendezvous, alguns homens preferiam alugar pequenos apartamentos para levarem suas amantes. Surgiam as garçonnières - pequenos apartamentos para servirem de refúgio ao amor clandestino - consideradas verdadeiras instituições do Segundo Império francês ${ }^{27}$. Apesar de a palavra ser de origem francesa, garçonnière surgiu nos Estados Unidos e não se assemelhava em nada ao uso dado na Fran- 
ça. Nas fazendas de algodão da Louisiania, onde se falava francês, era habitual que os meninos - garçons - dormissem em quartos situados no sótão, cujo acesso se dava por uma escada (localizada na varanda da casa), a qual era denominada garçonnière. $\mathrm{O}$ espaço para o sexo não encontrava mais acolhimento explícito no âmbito doméstico e refugiava-se clandestinamente nos espaços públicos, eminentemente masculinos. Devido à demanda, construtores trataram de edificar prédios com pequeninos apartamentos que, além de servir aos homens solteiros como moradia, ofereciam aos casados locais seguros e fora de suspeita para gozarem de sua vida paralela. Os locatários das garçonnières deveriam pagar, em dinheiro, com bastante antecedência ou depositar a quantia em contas idôneas, de modo a evitar problemas econômicos ou de privacidade. Muitas dessas garçonnières possuíam decorações bem semelhantes às das moradias. Assim não levantavam suspeitas e, para alguns, provocavam sensação de permissividade, na medida em que se vivenciava a imoralidade em uma atmosfera doméstica e liberavam-se os instintos reprimidos.

Com toda a repressão, foi no século XIX que a palavra sexualidade foi calcada, demarcando a diferenciação entre sexo e sexualidade, sendo o primeiro termo tido como biológico e o segundo visto como conduta. Quem melhor tratou do assunto, décadas mais tarde, debruçando-se especificamente sobre a sexualidade do século XIX foi Michel Foucault em História da sexualidade I - a vontade de saber ${ }^{28}$. Foucault colocava a questão não nos termos do "por que somos reprimidos", mas "por que dizemos, com tanta paixão, com tanto rancor contra nosso passado mais próximo, contra nosso presente e contra nós mesmos que somos reprimidos?". Foucault passou a investigar a sexualidade como experiência, correlacionando-a com a cultura e as formas de subjetividade. Com Foucault a sexualidade era uma construção social, intrinsecamente ligada ao subjetivo e ao poder; a repressão, uma verdade construída e aceita. Que então cada um buscasse a sua verdade. A sexualidade, segundo Foucault, passou a ser segredo de confissão ou da ética médica e o assunto permaneceu ligado à transgressão, ao pecado, ao desvio padrão. Afinal não se confessam as boas ações, mas aquilo de sujo, impróprio e impuro. O século XIX acirrou a visão do sexo transgressor. A paixão não se vivia em casa - no lar doce lar -, mas fora dela. Gravuras, fotos, contos e romances de cunho erótico eram vendidos clandestinamente. Os bordéis foram camuflados e varridos dos bairros burgueses, tornandose exilados da cidade higiênica e moderna. A garçonnière se transformava na minúscula utopia do prazer.

Em fins do século XIX, no período da Belle Époque, a sexualidade no âmbito doméstico começou a se transformar, fruto de alargamentos dos grilhões moralistas nos tratos sociais. Aos poucos, admitia-se a exteriorização da inten- 
ção do desejo. Os flertes tornaram-se mais freqüentes e tolerados, inclusive entre jovens. Os casais já se permitiam certas ousadias em busca do prazer, principalmente por parte da mulher. O quarto de dormir se despia de seu ar vetusto e adquiria ares menos compromissados com a rigidez e austeridade.

O orientalismo (árabe ou japonês) usado na decoração permitia a fuga visual dos grilhões moralistas do ocidente, incorporados pelos classicismos nas artes, e sugeria sensação de aventura e exotismo: fora do cotidiano, fora do convencional, fora do local. O Simbolismo, com seus traços sedutores que tentavam traduzir histórias literárias e teatrais, também criavam pictoricamente, figuras femininas que, atrás da capa de suas personagens, pareciam clamar por uma volúpia aprisionada em pensamentos.

Os instintos carnais ganharam um representante formal com a organicidade do art nouveau, por vezes mesclado às misturas do ecletismo e do orientalismo. Principalmente na versão francesa e na belga, a nova linguagem burilava as referências naturais, sublinhava a sensualidade feminina e lidava com as ondulações reverberantes, como que representando as ondas de prazer. As mulheres saídas dos traços gráficos de uma arte nova transbordavam sensualidade, mostravam-se quase emancipadas, transparecendo nas curvas de seu corpo um novo querer ser. O desejo de seduzir e gozar das consequiências do convencimento amoroso despertava na mulher - inclusive na esposa - atitude que se distanciavam da imagem da mãe de família, aproximando-a das 'necessidades' antes reconhecidas como masculinas. As mulheres queiram fazer sexo e retomar lugares propícios às suas fantasias sexuais. A redefinição da sexualidade conjugal correspondeu à revisão das casas de prostituição, que buscaram renovar as técnicas de volúpia, imprimindo uma decoração suntuosa. O brilho dos espelhos, a luz profusa, os olfatos sugestivos, a fartura dos tapetes, os tecidos trabalhados compunham uma decoração que se mirava na respeitabilidade dos salões das casas da elite. Quadros vivos atiçavam os desejos dos voyeurs, as prostitutas mostravam-se mais provocantes e capazes de ousadias, antes proibidas, apesar de a nudez deliberada estar em baixa. Algumas casas de rendez-vous passaram a funcionar somente de dia e ofereciam damas respeitáveis - belas mulheres pobres ou esposas frustradas. A sedução entrava nos bordéis. Sua decoração deveria promover desejos, inclusive o de gastos sem medidas. Criava-se uma intimidade fora de casa, um lugar privado sem ser familiar, trazendo uma outra faceta para o significado da relação entre lar e privacidade.

Após a Primeira Guerra Mundial ${ }^{29}$, a crescente mobilidade da população, a expansão dos esportes, a independência relativamente prematura dos jovens e o ingresso mais contundente da mulher no mercado de trabalho contribuíram para as transformações das regras de decência e, por conseguinte, os padrões sociais 
foram se desprendendo do moralismo oitocentista. Em virtude dos novos hábitos comportamentais, as décadas de 1920/30 foram denominadas de Anos Loucos. Ia-se à praia ou praticavam-se esporte mostrando partes do corpo consideradas imorais poucas décadas atrás. $\mathrm{O}$ homossexualismo, principalmente feminino, parecia estar em moda. Insinuava-se uma explosão de liberalidade.

Os mais endinheirados, como no século XIX, adquiriam ou arrendavam locais propícios ao sexo. A garçonnière ressurgia, mantendo à distância o espaço doméstico. Os rapazes se retiravam para os pequenos apartamentos de prazer com as garotas ou garotos que permitiam tal licenciosidade. As aventuras amorosas permaneciam interligadas com o âmbito da rua. O peso moral da casa afastava a liberalidade dos desejos para seu exterior. Continuava mais excitante fazer sexo distante do lar. Muitos artistas e intelectuais, que viviam com parcos recursos, eram também locatários de garçonnières, o que valeu mais um atributo a esse local - o da intelectualidade e criação artística. A partir de então, a garçonnière passou a ser reconhecida como espaço erótico-intelectual. Muitos artistas - do sexo feminino ou masculino - libertavam-se da tradição e fundavam suas vanguardas e suas novas verdades. As atitudes, da mesma forma, acompanhavam a linha de suas produções artísticas: a sexualidade era declarada, aberta e propícia a novas experiências. Com comportamentos fora dos padrões, os pequenos burgueses consideravam todos os artistas libertinos, o que enfatizava a adjetivação das garçonnières de erótico-intelectuais. No Brasil, famosa foi a garçonnière de Oswald de Andrade, principalmente a localizada na Rua Líbero Badaró, em São Paulo, onde, além de favorecer encontros dos artistas modernistas, podia lhe garantir privacidade dos seus próprios casos amorosos. Na obra $O$ perfeito cozinheiro das almas deste mundo ${ }^{30}$, um verdadeiro diário de sua garçonnière, o grupo freqüentador do lugar expôs suas intimidades por cartas, recortes, recados, poesias, desenhos e charges, desvelando os segredos que aquelas paredes antes guardavam só para si.

Os anos entre guerras foram marcados por atitudes de liberação dos costumes para poucos que se atreviam a viver o prazer e a realizar mudanças. Paris era considerada a cidade mais avançada. Fora dela e fora do círculo dos 'liberados' - vistos ainda como marginais - os dogmas morais oitocentistas estavam longe de arrefecer. O sexo prostrava-se na marginalidade. Os ambientes modernistas que conquistavam uma clientela crente no progresso pareciam assépticos, semelhantes a máquinas de morar, e se mostravam tão artificiais que pareciam ter banido o sexo de seus interiores ou que a atividade só acontecia com hora marcada e local agendado. Se como dizia Mies van der Rohe, 'menos é mais', os ambientes quase nus das casas 'racionalistas' poderiam simbolizar um estado de nudez e, portanto, facilitador para o ato sexual. Mas, opostamente, os quartos do 
modernismo não instigavam erotismo. Ao contrário. Eram interpretados, pelo público em geral, como algo tão frio quanto hospitais. Os ambientes modernos pareciam assexuados. Seus moradores, em especial os cônjuges, estavam predeterminados a atuarem em espaços neutros, que permitiam ampla circulação por seus vazios, mas com pouca ou nenhuma brecha para emancipação pessoal.

Se a casa virava máquina, com o advento do automóvel, popularizado nos anos 50, os casais enamorados ganhavam um outro espaço para experimentar sua sexualidade. Uma máquina acolhia o sexo, provida de formas aerodinâmicas, com cores brilhantes e acabamentos luzidios e bancos estofados de couro, oferecendo um outro ambiente interior como referente para as intimidades. Aos que permitiam certas liberdades, o carro se tornou fundamental para efetivarem seus desejos sexuais, seja nos locais ermos e escuros ou encaminhando-se para os hotéis mais afastados da cidade. Fora do carro, o escurinho do cinema e a penumbra dos bailes eram situações que possibilitavam aos jovens começar a vivenciar, com moderação, sua libido, não mais escondida, mas ainda controlada.

$\mathrm{Na}$ década de 1960 novas condutas sexuais ensejaram espaços diferenciados. A difusão do método contraceptivo separou o prazer da reprodução e a mulher se avizinhou à condição masculina. Podia-se usufruir do prazer sem o risco de uma gravidez indesejada. Aliada a isso, a geração 'paz e amor' advogava o livre relacionamento, negando as bases morais em vigor. Os desejos não deveriam ser mais reprimidos. Liberdade total era um lema de vida. O comportamento unissex abolia as diferenças entre masculino e feminino. Espaços pscicodélicos, ou denominados de pop, ofereciam experiências sensórias, novos estímulos visuais. As certezas eram suspensas e os ambientes para se viver, frente aos preceitos da contracultura, eram lugares que assumiam o sexo como coisa do cotidiano (Sexo é vida! Diria um jargão). O sexo não se fazia apenas em quartos, com camas retangulares (ultrapassadas e 'quadradas', para usar temo da época). Ele estava decorativamente representado como possível em todos os lugares ${ }^{31}$.

Por um lado, os membros da contracultura desafiavam os padrões morais vigentes; de outro, as facções tradicionais da sociedade agarravam-se aos antigos códigos de conduta. O casamento era questionado, até considerado instituição falida. Desejavam-se novas relações em que não houvesse dominante nem dominado, esfacelando-se a idéia de propriedade privada de corpos e sentimentos, de lugares masculinos e femininos. Estava-se em plena revolução - a sexualidade explicitava-se. $\mathrm{O}$ amor livre não elegeu um lugar particular, uma decoração evocativa, nenhum ambiente intimamente sexuado porque todos os lugares deveriam acolher o sexo.

No Brasil, para os menos ousados ou os que mantinham relações extraconjugais, os hotéis 'suspeitos' ofertavam, nos centros das grandes cidades, locais 
para o sexo oculto. Contudo, a repressão policial acabou fechando muitos desses estabelecimentos, dificultando o encontro sexual de casais fora dos lares. Somente para os que podiam contar com carro ou táxi era possível uma escapada para além dos limites da cidade - nos motéis, ainda sem o caráter estritamente sexual.

Não demorou muito para que alguns comerciantes percebessem a falta no mercado de produtos e serviços para as demandas sexuais dos casais formais e não formais. Em fins da década de 1960 começaram a ser construídos os motéis específicos para o sexo. Inicialmente, sem uma legislação própria, camuflavamse como hotéis e deles retiravam suas referências ambientais visuais. Aos poucos, com o sucesso comercial do empreendimento, foram se ampliando as imagens relacionadas à sua atividade fim, ganhando ambiências que divergiam cada vez mais da atmosfera doméstica e dos hotéis. Encontravam-se ambientações medievais, orientais (em geral relacionadas aos povos árabes) ou que se remetiam aos boudoirs do século XVIII ou às curvas naturalizantes do art nouveau. Foram as linguagens escolhidas para serem associadas aos ambientes para o sexo, historicamente ligadas ao imaginário da sexualidade ${ }^{32}$. Lugar de reclusão e mistério, haréns das mil e uma noites, alcovas de devassidão, cômodos de volúpia. Cada ambientação aparentava um caráter e as imagens porta adentro procuravam traduzir fantasias retiradas de sonhos, histórias e fantasias.

As antigas garçonnières se democratizavam. Não mais era necessário possuir recursos financeiros que sustentassem um apartamento extra. Um quarto podia ser alugado por algumas horas, garantindo acesso também aos remediados e ofertando segurança, anonimato e privacidade para os encontros sexuais. Alguns atrativos foram sendo anexados ao quarto, típicos dos espaços de âmbito público - piscina, boate, palco - oferecendo vivências que publicamente seriam moralmente impraticáveis. Sexo era diversão. A decoração do interior tomava emprestados signos da exterioridade para satisfazer novas demandas visuais que estimulassem prazer. Misturar códigos comportamentais do lado de fora, típicas do estar em público, com condutas condizentes com o lado de dentro, promovia uma união pouco ortodoxa, transgressora, excitante. Na década de 70 ampliouse a oferta de produtos eróticos: revistas, objetos fetiches, filmes - já rotulados como tais e censurados para menores de 18 anos. A pornografia passou a funcionar no âmbito da lei, os motéis ganharam normas de projeto. Apesar de essa pretensa abertura, as obras ligadas ao sexo permaneceram à luz do pecado, desafiando tabus em torno do livre exercício sexual e mantendo sua ligação com a transgressão. O lugar para o sexo era conhecido por todos, falado publicamente por poucos, frequientados por muitos. Com esse sucesso de público, muitos motéis tentaram se vestir de imagens que incitassem o prazer. 
Publicações sobre o erotismo e a sexualidade surgiram ou ressurgiram acompanhando a maior liberalidade dos padrões sociais: romances, poesias, artes plásticas, história em quadrinhos, filmes, peças teatrais. Provenientes da micro-história, da antropologia e sociologia, vários trabalhos foram realizados sobre a intimidade e a privacidade e com eles a sexualidade e o erotismo detiveram grande atenção dos pesquisadores. A década de 80 assistiu a uma explosão de estudos, produções e edições cujo sexo estava na berlinda. O sexo virou conhecimento e virou museu. Em 1985, na cidade de Damrak, Holanda, abria-se o que é considerado o primeiro museu do sexo. Dali em diante, Hamburgo (1992), Copenhague (1993), Berlim (1996), Barcelona (1996), Paris (1998), Nova Iorque (2002), São Petersburgo (2004), Hollywood (2004), Miami (2005), Veneza (2006) e Londres (2007) inauguraram seus museus correlatos, cujos acervos eram exclusivamente alusivos ao sexo, ao erotismo ou à arte erótica.

Outros setores das ciências humanas e aplicadas foram usufruindo da história das mentalidades e trazendo suas contribuições. Trabalho direcionado à arquitetura é o de Christian Thomsen e Angela Krewani, intitulado Sensuous architecture: the art of erotic buildings ${ }^{33}$ (Arquitetura sensual: a arte do edifício erótico). O livro apresenta uma investigação inédita desse aspecto da arquitetura, do passado aos dias de hoje, incluindo o cybersex dentro da arquitetura virtual. As imagens apresentadas fixam-se mais em fachadas do que nos interiores e as associações com formas sensuais baseiam-se nas semelhanças dos edifícios com formas fálicas, o que depende, muitas vezes, de um ângulo bem particular da fachada.

O lugar do sexo hoje? Fala-se, pesquisa-se, estuda-se, vende-se, consomese - real ou virtualmente. A Biblioteca Nacional de Paris ${ }^{34}$ exibiu pela primeira vez (04/12/2007 a 22/03/2008) as obras eróticas de suas coleção, até então devidamente interditadas ao público e guardadas no chamado 'Inferno' da biblioteca. Esperava-se em filas quase infindáveis para se visitar a exposição L'Enfer à la Biliothèque, Eros au secret (Inferno na biblioteca, Eros em segredo), mostrando o quanto o mundo do anonimato, dos falsos endereços, dos lugares clandestinos ligados ao sexo e ao erotismo não estão apenas associados a conventos, bordéis e boudoirs. Eles também se encontram nas 'intimidades' das bibliotecas. Apesar de essa aparente vulgarização escrita, falada e televisionada a atividade sexual ainda não se transformou em prática socialmente explícita. Os jovens namorados não vão ao motel como se fossem a um bar ou ao cinema - a programação sexual ainda é um evento especial, quase uma contravenção. Ainda se faz escondido, longe de olhos estranhos. É preciso quatro paredes. É necessário haver relações interiores, íntimas, internas, particulares e, portanto, valores relacionados ao lado de dentro, ambientes dentro, decorações porta adentro que, 
de preferência, ofereçam imagens estimulantes, idéias sugestivas para diversas intimidades.

Mesmo com a publicidade dos motéis, até considerando sua entrada nos centros urbanos, convivendo com os edifícios residenciais, a sexualidade está longe de encontrar sua liberdade total de expressão. Talvez, na medida em que houver sua total banalização, o sexo perca seu caráter excitante, obsceno e libertino. A instância da transgressão ainda faz de certas atividades humanas seu principal atrativo. As imagens interiores que estiveram relacionadas a uma intimidade favorável ao sexo estavam alicerçadas em arranjos que lidavam com linhas ondulantes, apelos decorativos, sofisticações visuais, detalhismos de forma, cores vibrantes, certo exotismo, aconchegos próprios de estofos e superfícies macias, características não por acaso vinculadas ao feminino. Poderíamos arriscar a concluir que os lugares ideais para a intimidade sexual passaram por imagens de vínculo feminino: decorações que permitiam verificar a presença de desejo em curvas, passavam a idéia de deixar penetrar em seu interior e de se sentir confortavelmente acolhido nas suas dobras e reentrâncias. O sexo precisava de ambientes interiores. Assim, só em espaços porta adentro o sexo poderia estar dentro, sentir o prazer de estar dentro e por dentro.

Recebido em 28 de março 2008

\section{NOTAS}

${ }^{1}$ Cf., RYBC ZYN SKI, W itold. Casa: pequena história de uma idéia. Rio de Janeiro: Record.

${ }^{2} \mathrm{Cf}$. SEN N ET, Richard. The conscience of the eye - the design and social life of cities. N ew York: W.W. N orton \& Company, 1992.

${ }^{3} \mathrm{Cf}$., D IBIE, Pacal. O quarto de dormir - um estudo etnológico. Rio de Janeiro: G lobo, 1988.

${ }^{4} \mathrm{C}$., BARN ARD, Malcom. Approaches to understanding visual culture. London: Palgrave, 2001.

${ }^{5}$ Ibid., p.3.

${ }^{6}$ KN AU SS, Paulo. 0 desafio de fazer histó ria com imagens: arte e cultura visual. Artcultura, U berlândia, v. 8, n.12, p.98-115, 2005, p.112.

${ }^{7} A$ respeito de reflexõ es so bre visualidades dos ambientes interio res do mésticos, especialmente os de fins do século XIX, no Brasil, vide MALTA, Marize. Imagens porta adentro e uma história com móveis. In:Simpósio N acional de História, 24., 2007, São Leopoldo. Anais... São Leopoldo: U nisinos, 2007. 1 CD.

${ }^{8} \mathrm{U}$ samos o termo 'to mada' com franca alusão ao jargão cinemato gráfico, em virtude de se aproximar da experiência de olhar para ambientes interiores (panorâmica, de longe, perto, de passagem, bem devagar...). So bre reflexões acerca da locação no campo da produção visual, vide C H ERRY, D eborah; CULLEN, Fintan. O n location. Art H istory, 0 xford, vol.29, n.1, 532-539, sep. 2006.

${ }^{9}$ A expressão "porta adentro", usada relacionada - cotidiano "porta adentro", universo "porta adentro" - fo i empregada por Maria Izilda de Matos para identificar espaço e tempo do universo doméstico, onde 
ela situo u a análise da rotina dos trabalhos domésticos. Aplicamos aqui para também demarcar o locus que privilegiamos para o estudo da decoração (de interiores). MATO S, Maria Izilda Santos de. Cotidiano e cultura: história, cidade e trabalho. Bauru: EDUSC, 2002.

${ }^{10}$ Segundo interpretação de John Lukacs, os ambientes medievais só foram mobiliados interiormente depois que as mentes foram internamente mobiliadas. LUKACS, John. The bourgeois interior. American Scholar, v. 39, n. 4, oct. 1970. p.622-623.

${ }^{11} \mathrm{Cf}$., RICE, Charles. The emergence of the interior: architecture, modernity, domesticity. London: Routledge, 2007.

12 ELIAS, N orbert. Estruturas de habitação como indicadores de estruturas sociais. In: A sociedade de corte: investigação sobre a sociologia da realeza e da aristocracia de corte. Rio de Janeiro: Zahar, 2001, p.66-84.

${ }^{13} \mathrm{O}$ s leitos de aparato ou de cerimônia eram camas pensadas para ostentar visualmente o poder e a gló ria dos so beranos e, conseqüentemente, exaltar o Estado. N elas os reis realizavam rituais e recebiam comitivas estrangeiras. Famosas eram as cerimônias de Luís XIV em seu quarto, como o 'grand lever', que remontam à época de Henrique III. Cf. SAU LE, Béatrix. A propôs de la chambre de Louis XIV à Versailles. Réflexions sur la fonction d'une chambre royale. Dossier d'art - La chambre dans I'histoire de France, Dijon, n.22, p.22-33, fev.-mars 1995.

${ }^{14} \mathrm{Cf}$., ELEB, M onique ; D EBARRE, Anne. Architecture de la vie privée. Maisons et mentalités XVII-XIXe siècles. Bruxelles: Éditions H azan, 1999.

${ }_{15}$ Muitas dessas gravuras estão hoje abrigadas nos acervos de museus sobre sexo e erotismo ou se encontram fortemente guardados no L'Enfer, o chamado 'inferno' das bibliotecas públicas - lugar fechado para guardar livros considerados perigosos, ou seja, obscenos para a leitura.

${ }^{16}$ DELO N , M ichel. L'invention du boudoir. Paris: Zulma, 1999.

17 Segundo consta, madame de Pompadour fez construir para Luís XV um lugar, bem próximo ao palácio de Versailles, para sediar seus encontros amorosos. 0 s boatos sobre o lugar ampliaram-se por volta de 1750, tomado como verdadeiro bordel particular, repleto de jovens meninas para satisfação do rei. Cf., TRUSSO N, Réjane. Le Parc aux cerfs: la garçonnière de Louis XV . D isponível em : < http:/ /members.aol.com/dtrusson/flo uis.htm $>$.

${ }^{18} \mathrm{Cf}$., HILL, Charlotte ; W ALLACE, W illiam. Erotica: an illustrated anthology of art and literature. N ew York: Carrol \& G raf, 2002. 3v.

19 SADE, D onatien Alphonse Franço is. La Philosophie dans le boudoir. In : Apo LuIn AIRE, Guillaume. L'oeuvre du Marquis de Sade. Paris, Biblio thèque des Curieux, 1912.

${ }^{20}$ René M agritte, célebre pintor surrealista, também realizo u sua homenagem ao marquês de Sade por meio da obra intitulada 'La philosophie dans le boudo ir', de 1947.

${ }^{21}$ Cf., ELIAS, N orbert. A civilização como transformação do comportamento humano. In: 0 processo civilizador. U ma história dos costumes. Rio de Janeiro: Zahar, 1994, passim.

${ }^{22}$ Ao fim do Antigo Regime, panfletos associavam a vida libertina de Maria Antonieta com as corrupções do Estado, trazendo à tona os fantasmas eróticos do povo francês naquele momento.

${ }^{23}$ ELIAS, N orbert. Mudanças de atitudes nas relações entre sexos. In: 0 processo civilizador. Uma história dos costumes. Rio de Janeiro: Zahar, 1994, p.169-189.

${ }^{24}$ Livros com regras para a decoração de interiores e para a vida doméstica foram freqüentes no século XIX. U m dos mais minuciosos em termos de orientações para a composição decorativa nas casas é L'art dans la Maison. Cf., HAVARD, H enry. L'art dans la maison. 4 ed. Paris: Librairie Illustrée, 1884.

${ }^{25} \mathrm{C}$ f. SEN N ET, Richard. 0 declínio do homem público: as tiranias da intimidade. São Paulo: Companhia das Letras, 1988.

${ }^{26}$ Edgar Allan Poe escreveu contos, como Berenice, Ligéia, A máscara da morte rubra e A casa de U sher, que envolviam casos de anomalias mentais/co mportamentais asso ciadas às situações de permanência e convivência com a decoração de interiores. POE, Edgard Allan. A carta roubada e outras histórias de crime e mistério. Porto Alegre: L\&PM, 2003. So bre a asso ciação entre a literatura de Poe, visualidades, histeria e efeitos ópticos, vide GORDON, Era Beth. Poe: optics, hysteria and aesthetic theory. Cercles, n. 1, L'oeil, 2000, p.49-60. 
Do boudoir ao motel: cultura visual, imagens decorativas e lugares íntimos para o sexo

${ }^{27}$ BARDELLI, Carla ; PIPERN O, Antonella. Elogio della garçonnière. Panorama.it. Roma, feb 2004. Disponível em < hrp://ww w.panorama.it/so cieta/style/articolo/ix-A020001022941>.

${ }^{28}$ Cf., FO U C AU LT, Michel. A história da sexualidade 1: a vontade de saber. Rio de Janeiro: G raal, 1976.

${ }^{29}$ Cf., PRO ST, Anto ine ; VIN CEN T, Gérard. (O rg.) H istória da vida privada 5: da Primeira Guerra a nossos dias. São Paulo : C ompanhia das Letras, 1987.

${ }^{30}$ AN D RADE, 0 swald. 0 perfeito cozinheiro das almas deste mundo. São Paulo: Ex-Libris, 1987. [facsimile do diário de 1918]

${ }^{31}$ A ambientação de Vernon Panton para a exibição Visiona II, na feira do móvel de Colônia, em 1970, apresentava seu conceito de 'ambiente total', com suas subversões espaciais, e oferecia ondulações predominantes em to das as superfícies, falta de hierarquia entre paredes, tetos e pisos, inexistência de superfícies reconhecíveis como móveis e lustres. Esse espaço, de alucinantes visões, punha o indivíduo em outra sorte de experiência espacial, completamente subversiva. 0 ambiente propiciava rever vários preceitos e pré-conceitos tanto ambientais quanto comportamentais, tanto conceituais quanto existenciais. Podia-se fazer sexo sobre todas as superfícies disponíveis e com todas as cores.

${ }^{32}$ Sobre estudo acerca das linguagens decorativas associadas aos motéis cariocas, vide CAVALCAN TI, Lauro; GU IM ARÃES, Dinah. Arquitetura de motéis cariocas, espaço e organização social. Rio de Janeiro: Espaço, 1982.

33 TH O MSEN Christian ; KREWAN I, Ângela. Sensuous architecture: the art of erotic buildings. N ew York: Prestel, 1998.

${ }^{34}$ Para maiores informações sobre a exposição, acesse o site da Biblioteca N acio nal da França: http:// www.bnf.fr 